https://www.doi.org/10.33910/1992-6464-2021-201-45-55

С. Б. Башмакова, О. А. Петушкова

\begin{abstract}
АНАЛИЗ РЕЗУЛЬТАТОВ КОРРЕКЦИОННОЙ РАБОТЫ ПО РАЗВИТИЮ РЕЧЕВОЙ КОММУНИКАЦИИ У ДЕТЕЙ С РАССТРОЙСТВАМИ АУТИСТИЧЕСКОГО СПЕКТРА
\end{abstract}

\begin{abstract}
Статья посвящеена презентаџฺи данных исследования возможностей коррекции нарушений речевой коммуникации у старших дошкольников с расстройствами аутистического спектра. В работе представлены сравнительные данные педагогического эксперимента с выделением основных параметров изучения феномена речевой коммуникации и разработанной авторами диагностической методики оценки речевой коммуникации у дошкольников. Авторами выявлены и описаны характерные особенности нарушения речевой коммуникации у старших дошкольников с расстройствами аутистического спектра. Сформулированы рекомендации по совершенствованию содержания работь по коррекции нарушений речевой коммуникации у старших дошкольников с расстройствами аутистического спектра.
\end{abstract}

Ключевые слова: речевая коммуникация, нарушения речевой коммуникации, дошкольники, расстройства аутистического спектра, коммуникативные навыки.

S. Bashmakova, O. Petushkova

\title{
ANALYSIS OF THE RESULTS OF CORRECTIVE WORK ON THE DEVELOPMENT OF SPEECH COMMUNICATION IN CHILDREN WITH AUTISM SPECTRUM DISORDERS
}

\begin{abstract}
The article reports the results of the research in the possibilities of remediating communication disorders in older preschoolers with autism spectrum disorders. The article provides comparative data of a pedagogical experiment. First, we identified the main parameters of communication to focus on in our study. Second, we developed a diagnostic methodology to assess communication skills in preschool children. Thus, the article discusses characteristic features of communication disorders in older preschoolers with autism spectrum disorders and provides guidelines to make the remediation of communication disorders in older preschoolers with autism spectrum disorders more effective.
\end{abstract}

Keywords: communication, communication disorders, preschool children, autism spectrum disorders, communication skills.

Феномен расстройства аутистического спектра одновременно рассматривается как клиническая форма психического расстройства и как детский вариант дизонтогенеза. В отечественных исследованиях расстройства аутистического спектра изучаются как сложный дефект.

К. С. Лебединская [2], О. С. Никольская [2] выявили, что нарушение коммуникации и речи у детей с расстройствами аутистического спектра является одним из дифферен- циальных диагностических критериев расстройства и входит в триаду симптомов аутизма [2]. Нарушения превербальной и вербальной коммуникации выделяют в диагностике трудностей коммуникации при аутизме. Ю. Ф. Гаркуша [1], В. В. Коржевина [1], С. А. Миронова [4] в своих исследованиях подчеркивают, что недоразвитие речевых средств приводит к появлению специфических черт речевой коммуникации, ограничению контактности, замедленности 
при включении в ситуацию общения, неумению поддерживать беседу и вслушиваться в воспроизводимую речь, невнимательности к речи собеседника и к снижению активности коммуникации. Е. М. Мастюкова [3] отмечает, что у детей с аутистическими расстройствами нарушено развитие коммуникативной функции речи и коммуникативного поведения в целом, независимо от срока появления речи и уровня ее развития. Нарушения речи занимают значительное место в нарушении речевой коммуникации детей с расстройствами аутистического спектра. Они отражают основную специфику аутизма, а именно несформированность коммуникативного поведения.

Комплексная психолого-педагогическая коррекция речевой коммуникации у детей с расстройствами аутистического спектра возможна лишь в специально организованных условиях и при разработке специальной программы. Нами была разработана структура и содержание программы коррекции нарушений речевой коммуникации старших дошкольников с расстройствами аутистического спектра. В основу построения программы был заложен концентрический принцип. Комплексная программа включает в себя три направления работы: формирование мотивации речевой коммуникации, формирование средств речевой коммуникации, формирование регуляции речевой коммуникации, реализуемые в три этапа. Определена продолжительность реализации данных этапов, формы организации работы. Описаны условия, методы и средства формирования коммуникативных навыков.

Экспериментальное изучение и анализ результатов показали, что оценка мотивации речевой коммуникации старших дошкольников с расстройствами аутистического спектра при общении со сверстниками улучшилась. Индекс мотивации речевой коммуникаций у детей с расстройствами аутистического спектра после педагогического эксперимента составил 1,8 балла, что в 4,5 раза выше, чем в начале эксперимента (0,4 балла). При анализе признака мотивации речевой коммуникации старших дошкольников с расстройства- ми аутистического спектра можно выделить незначительные улучшения. Показатель речевой инициативы у детей с расстройствами аутистического спектра составил 0,3 балла, что составляет $30 \%$ от нормативного показателя; это в 3 раза выше, чем на констатирующем эксперименте ( 0,1 балла, что составляет $10 \%$ от нормативного показателя). Дети с аутистическими расстройствами при контакте со сверстниками в процессе организации игры стали обращаться к сверстнику и задавали вопросы, но не могли объяснить правила игры и игровые действия.

Количество речевых ответов в процессе речевой коммуникации у детей с расстройствами аутистического спектра увеличилось в 2 раза $(0,4$ балла, что составляет $40 \%$ от нормативного показателя) по сравнению с первым результатом диагностики ( 0,2 балла, что составляет $20 \%$ от нормативного показателя). Некоторые дошкольники с аутизмом в процессе игры начали отвечать на вопросы по сюжету игры в неразвернутой форме в процессе диалога со сверстниками.

Оценка готовности к речевой коммуникации старших дошкольников с расстройствами аутистического спектра выявила увеличение показателя в 4 раза ( 0,4 балла, что составляет $40 \%$ от нормативного показателя), тогда как на констатирующем эксперименте у детей с расстройствами аутистического спектра показатель был низким $(0,1$ балла, что составляет $10 \%$ от нормативного показателя). Старшие дошкольники с аутистическими расстройствами начали приносить игрушки для проведения игровых действий и издавали звуковые реакции в игровой ситуации.

Наблюдение за наличием неречевых реакций у старших дошкольников с расстройствами аутистического спектра в игровой деятельности со сверстниками показало увеличение результатов в 3 раза (0,3 балла - это составляет $30 \%$ от нормативного показателя) по сравнению с первыми результатами диагностики, когда этот показатель не проявлялся (0 баллов - $0 \%$ от идеального нормативного показателя). Дети с аутизмом начали проявлять 
жестовые реакции игровой ситуации, но зрительный контакт так и не выявлен.

Оценка устойчивости контакта в речевой коммуникации испытуемых до контрольного эксперимента выявила полное отсутствие данного показателя (0 баллов, что составляет 0\% от идеального нормативного показателя). После коррекционной работы показатель увеличился в 4 раза (0,4 балла, что составляет $40 \%$ от нормативного показателя). У старших дошкольников с аутизмом проявлялись реакции на игровые действия детей, некоторые дети стали давать вербальные и невербальные ответы на вопросы играющих, но продолжали уходить от речевой ситуации до ее окончания.

Таким образом, сравнительная характеристика результатов оценки состояния мотивации речевой коммуникации старших дошкольников с расстройствами аутистического спектра со сверстниками в процессе игровой деятельности до и после формирующего эксперимента выявила улучшение показателей практически в 2 раза. Результаты показателей диагностики представлены на рисунке 1.
По результатам проведенных диагностик мотивации речевой коммуникации старших дошкольников с расстройствами аутистического спектра при общении со взрослыми в продуктивном виде деятельности мы сравнили средний показатель всех проявлений мотиваций. Индекс мотивации речевой коммуникации старших дошкольников с расстройствами аутистического спектра при общении со взрослыми после формирующего эксперимента стал примерно в 2 раза (3 балла) больше, чем до формирующего эксперимента (1,3 балла).

Показатель речевой инициативы при общении со взрослым у старших дошкольников с расстройствами аутистического спектра после педагогического эксперимента увеличился в 2 раза ( 0,6 балла, что составляет $60 \%$ от нормативного показателя) по сравнению с первичным результатом (0,3 балла, что составляет $30 \%$ от нормативного показателя). Практически все дети могли обратиться к взрослому, задавали вопросы и выражали просьбу.

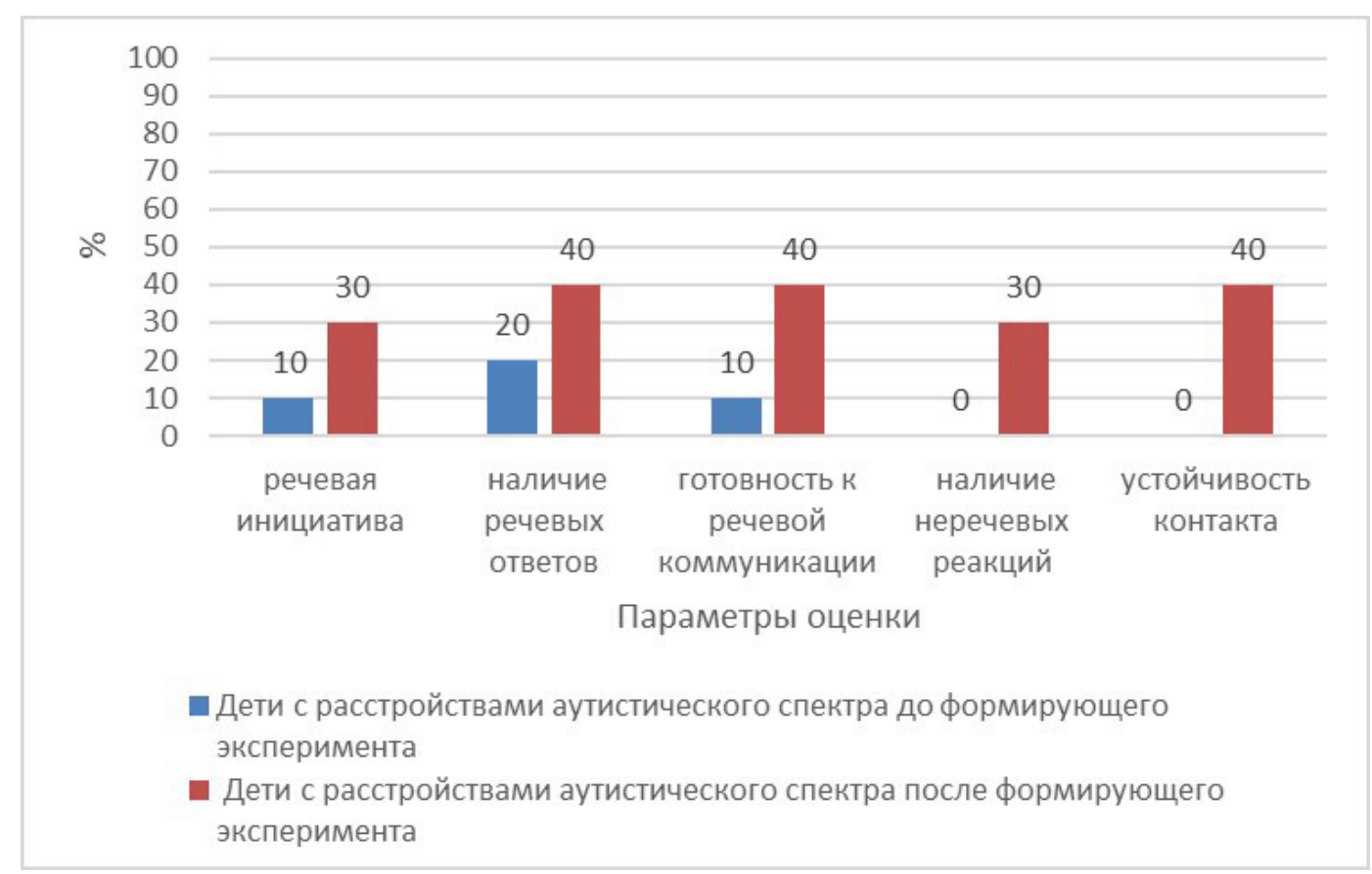

Puc. 1. Результаты оценки состояния мотивации речевой коммуникации со сверстниками у старших дошкольников с расстройствами аутистического спектра до и после формирующего эксперимента 
Количество речевых ответов в процессе речевой коммуникации со взрослым у детей с расстройствами аутистического спектра увеличилось примерно в 2 раза $(0,7$ балла, что составляет $70 \%$ от нормативного показателя) по сравнению с результатом до формирующего эксперимента $(0,4$ балла $40 \%$ от нормативного показателя). Дети с аутизмом в процессе продуктивного вида деятельности стали отвечать на вопросы взрослого в неразвернутой форме; у большинства детей проявляется развернутая речь в процессе диалога.

Оценка готовности к речевой коммуникации со взрослыми у старших дошкольников с расстройствами аутистического спектра выявила улучшение в 1,5 раза (0,7 балла, $70 \%$ от нормативного показателя) по сравнению с результатом до формирующего эксперимента (0,5 балла, что составляет $50 \%$ от нормативного показателя). Показатель наличия неречевых реакций в речевой коммуникации старших дошкольников с расстройствами аутистического спектра в продуктивной деятельности со взрослыми увеличился в 5 раз $(0,5$ балла $-50 \%$ от нормативного показа- теля) по сравнению с результатом до проведения педагогического эксперимента $(0,1$ балла, что составляет $10 \%$ от нормативного показателя). Дошкольники с аутистическими расстройствами стали вслушиваться в речь взрослого и использовать жесты в процессе продуктивного вида деятельности.

Оценка устойчивости контакта в речевой коммуникации старших дошкольников до формирующего эксперимента выявила полное отсутствие данного показателя у детей с расстройствами аутистического спектра (0 баллов, что составляет $0 \%$ от идеального нормативного показателя); после коррекционной работы выявлено улучшение показателя в 5 раз ( 0,5 балла, что составляет $50 \%$ от нормативного показателя). Половина детей с расстройствами аутистического спектра проявляли вербальные и невербальные реакции и обеспечивали речевую коммуникацию в процессе продуктивного вида деятельности.

Таким образом, сравнительная характеристика результатов оценки состояния мотивации речевой коммуникации старших дошкольников с расстройствами аутистического спектра со взрослыми в процессе игровой деятельности

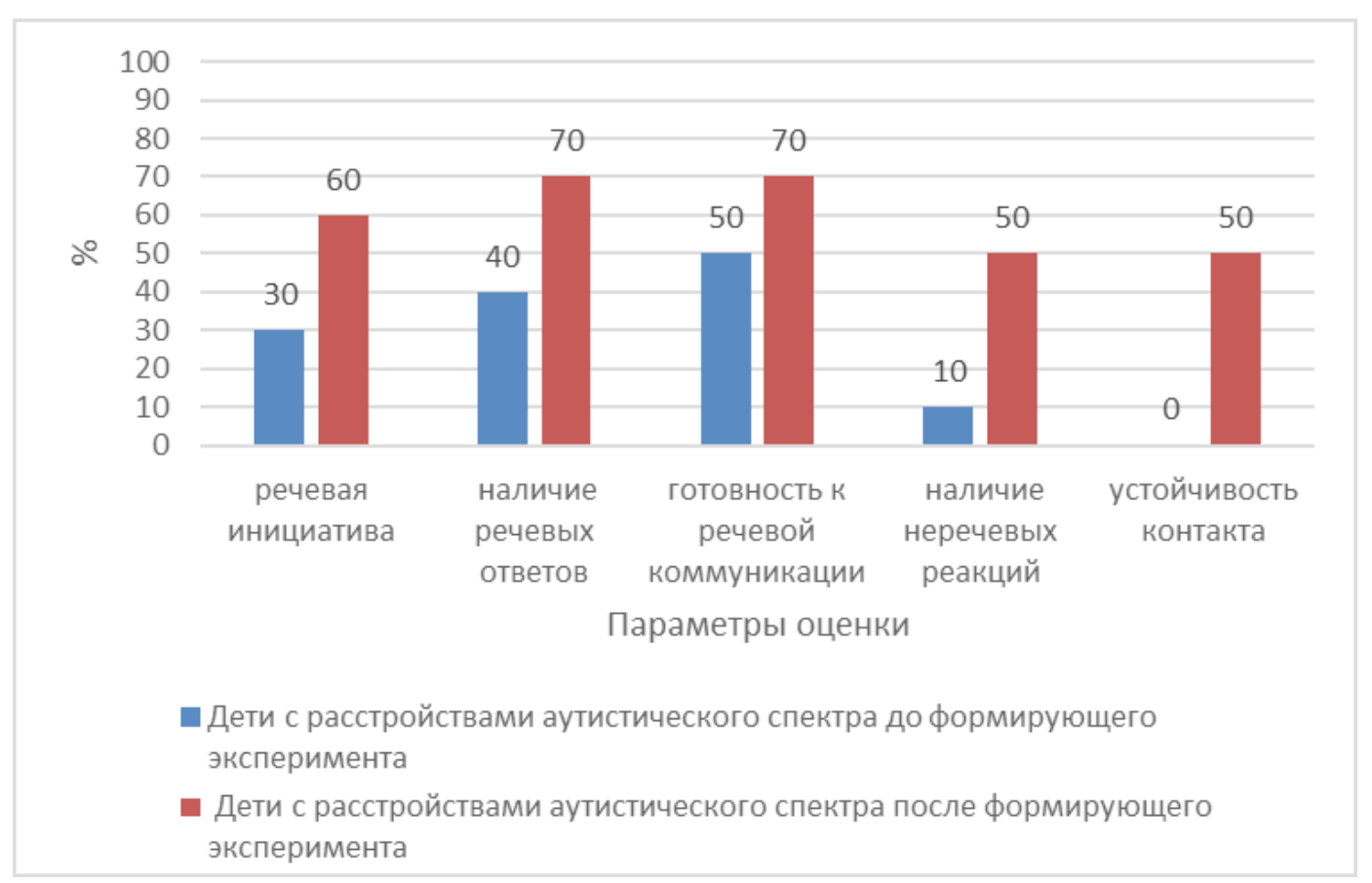

Рuс. 2. Результаты оценки состояния мотивации речевой коммуникации со взрослыми у старших дошкольников с расстройствами аутистического спектра до и после формирующего эксперимента 
до и после формирующего эксперимента выявила положительную динамику и эффективность использования программы коррекции нарушений речевой коммуникации старших дошкольников с расстройствами аутистического спектра. Полученные результаты представлены на рисунке 2.

При обследовании фонетических средств коммуникации старших дошкольников с расстройствами аутистического спектра выявлено улучшение качества звукопроизношения. Испытуемые научились правильно произносить губно-зубные и сонорные звуки. У детей с расстройствами аутистического спектра средний показатель сформированности фонематических средств коммуникаций составил 41,9 балла (99\% от нормативного показателя), что выше по сравнению с показателями до коррекционной работы - 41,2 балла (98\% от нормативного показателя).

Сравнительная характеристика результатов диагностики качества фонетических средств коммуникации старших дошкольников с расстройствами аутистического спектра до и после формирующего эксперимента представлена на рисунке 3.

При анализе проведенных диагностик лексической стороны речевой коммуникации старших дошкольников с расстройствами аутистического спектра до и после форми- рующего эксперимента было выявлено, что средний показатель словаря существительных стал в 1,5 раза выше $(13,1$ балла, что соответствует $87 \%$ от нормативного показателя), чем до формирующего эксперимента (10,3 балла - $69 \%$ от нормативного показателя). Дети с аутизмом освоили лексические темы: игрушки, одежда, овощи, фрукты, мебель, животные, деревья, цветы, продукты. Но сохранялись ошибки в обозначении частей тела, посуды и обуви. Результаты сравнительной диагностики словаря существительных в речевой коммуникации старших дошкольников с расстройствами аутистического спектра изображены на рисунке 4.

Оценка использования глагольных средств коммуникации выявило улучшение показателей в 2 раза $(1,8$ балла - $60 \%$ от нормативного показателя) по сравнению с первичными результатами диагностики (0,8 балла $60 \%$ от нормативного показателя). У детей с аутизмом выявлена положительная динамика в обозначении действий и предметов, незначительно повысились показатели действий, направленных на себя и на предметы. Сравнительные данные по оценке глагольных средств коммуникации у старших дошкольников с расстройствами аутистического спектра изображены на рисунке 5.

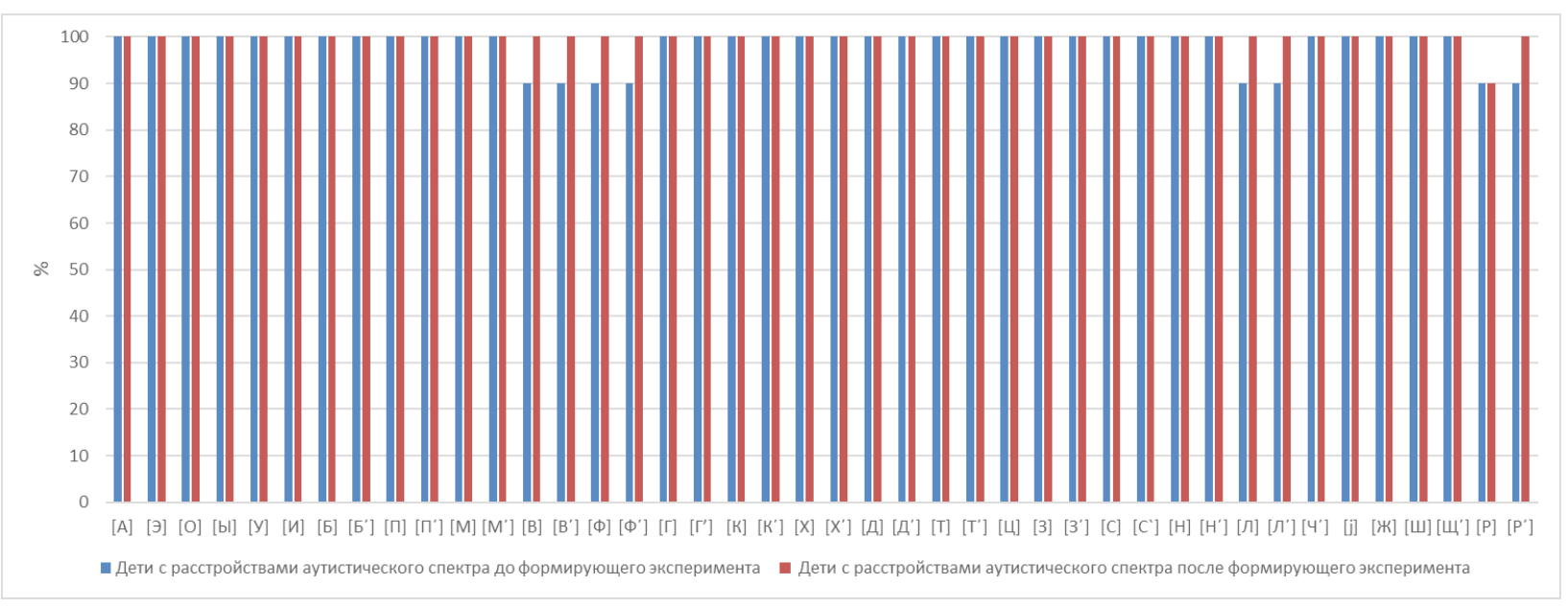

Puc. 3. Результаты оценки фонетических средств коммуникации у старших дошкольников с расстройствами аутистического спектра до и после формирующего эксперимента 


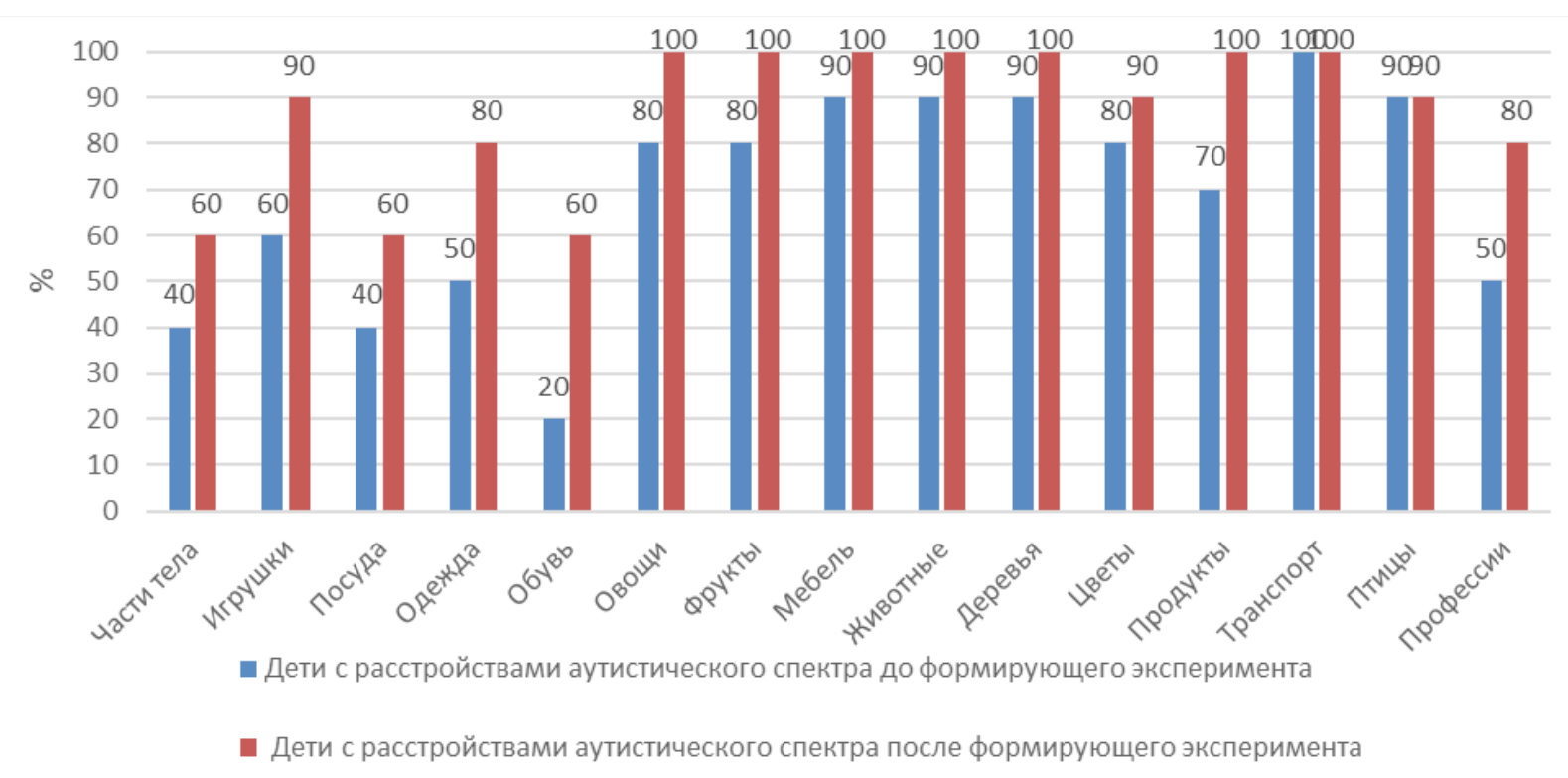

Рис. 4. Результаты оценки словаря существительных в речевой коммуникации у старших дошкольников с расстройствами аутистического спектра до и после формирующего эксперимента

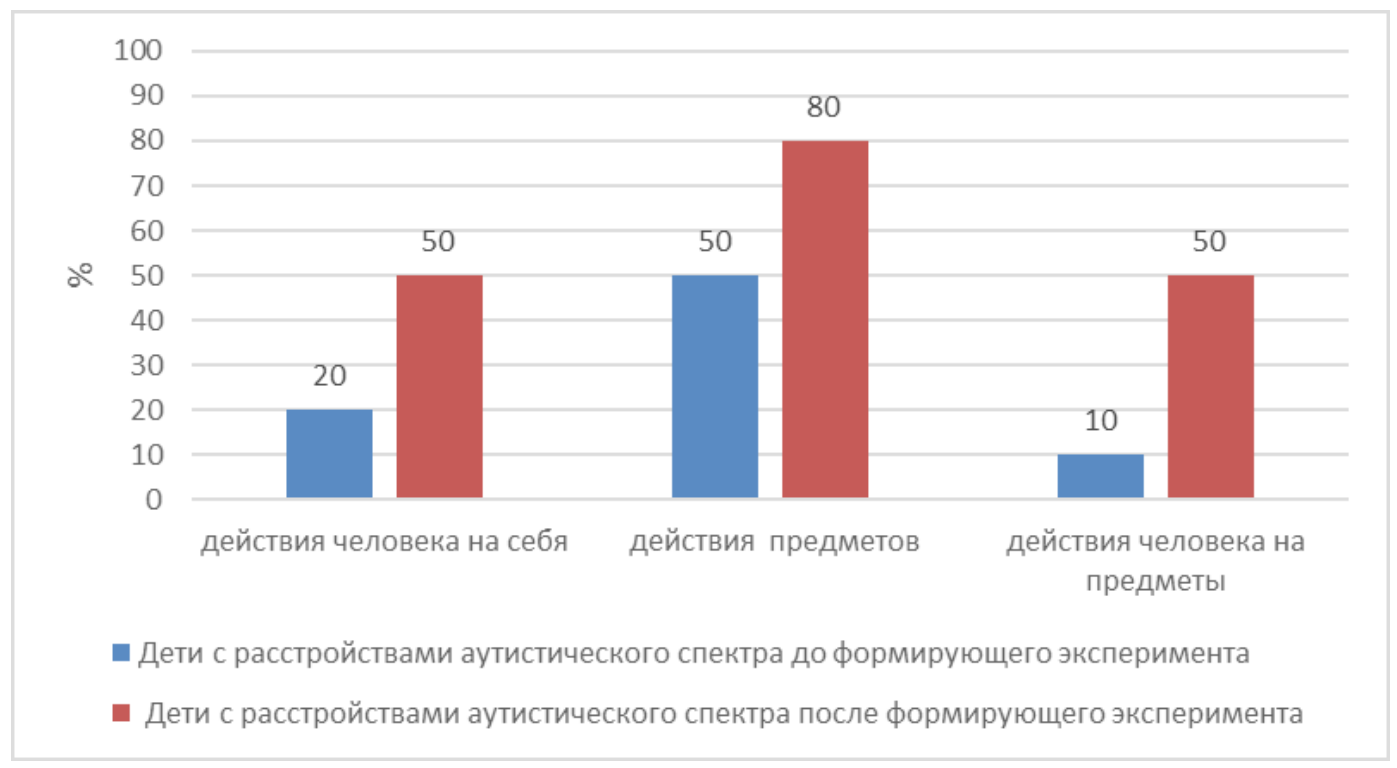

Рuc. 5. Результаты оценки глагольного словаря в речевой коммуникации старших дошкольников с расстройствами аутистического спектра до и после формирующего эксперимента

Сравнительное изучение оценки словаря прилагательных показало незначительное улучшение. После формирующего эксперимента словарь прилагательных у старших дошкольников с расстройствами аутистического спектра составил 3,9 балла (78\% от нормативного показателя), что ненамного выше, чем до эксперимента (64\% от нормативного идеального показателя), 3,2 балла из 5. Наблюдается незначительное увеличение числа прилагательных, обозначающих вкус и тактильное представление. Получен- 
ные сравнительные данные по оценке словаря прилагательных старших дошкольников с расстройствами аутистического спектра представлены на рисунке 6.

Развитие фразовых средств речевой коммуникации было оценено в 3 балла (100\% от нормативного показателя) - наблюдается улучшение на 93\%. Дети с аутизмом научились составлять рассказы по сюжетной картинке в основном простыми предложениями. Увеличилось количество предложений в рассказах в среднем до 8 предложений. Рассказы стали более связными, последовательными, логичными. Полученные сравнительные данные оценки фразовых средств речевой коммуникации старших дошкольников с расстройствами аутистического спектра изображены на рисунке 7.

Полученные сравнительные результаты состояния средств речевой коммуникации старших дошкольников с расстройствами аутистического спектра представлены на рисунке 8.

Сравнительный анализ результатов диагностики состояния регуляции речевой коммуникации при общении со взрослыми до и после педагогического эксперимента выявил улучшение показателей. После констатирующего эксперимента индекс регуляции речевой коммуникации старших дошкольников с расстройствами аутистического спектра составил 0,6 балла, что почти в 1,5 раза лучше, чем при первичной диагностике (0,4 балла). Состояние семантической правильности высказывания улучшилось в 1,5 раза (0,6 балла — $60 \%$ от нормативного показателя) по сравнению с результатом констатирующего эксперимента (0,4 балла 40\% от нормативного показателя). Дети с аутизмом стали активнее отвечать на вопросы взрослого, правильно подбирать слова.

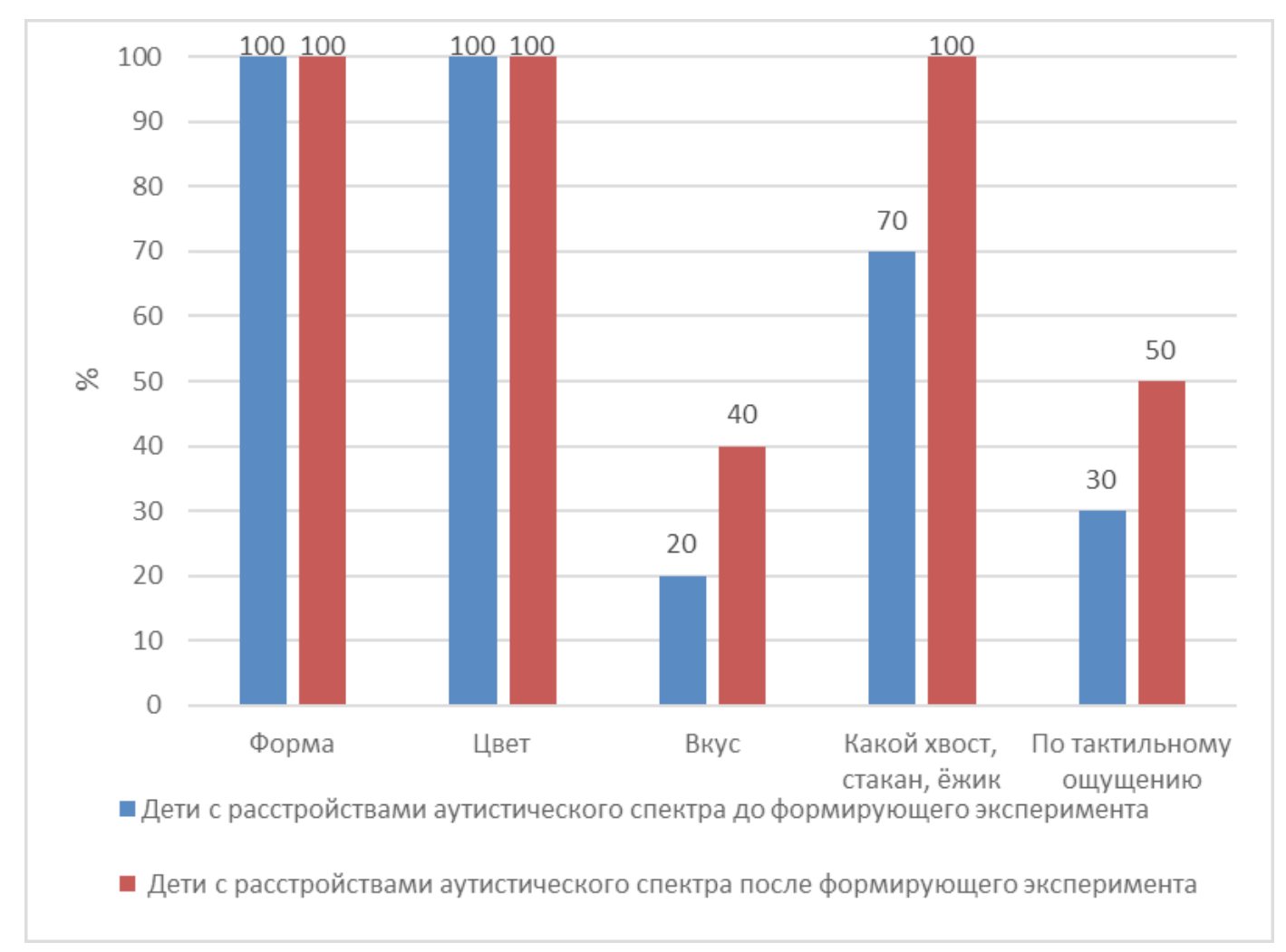

Pис. 6. Результаты оценки словаря прилагательных в речевой коммуникации старших дошкольников с расстройствами аутистического спектра до и после формирующего эксперимента 


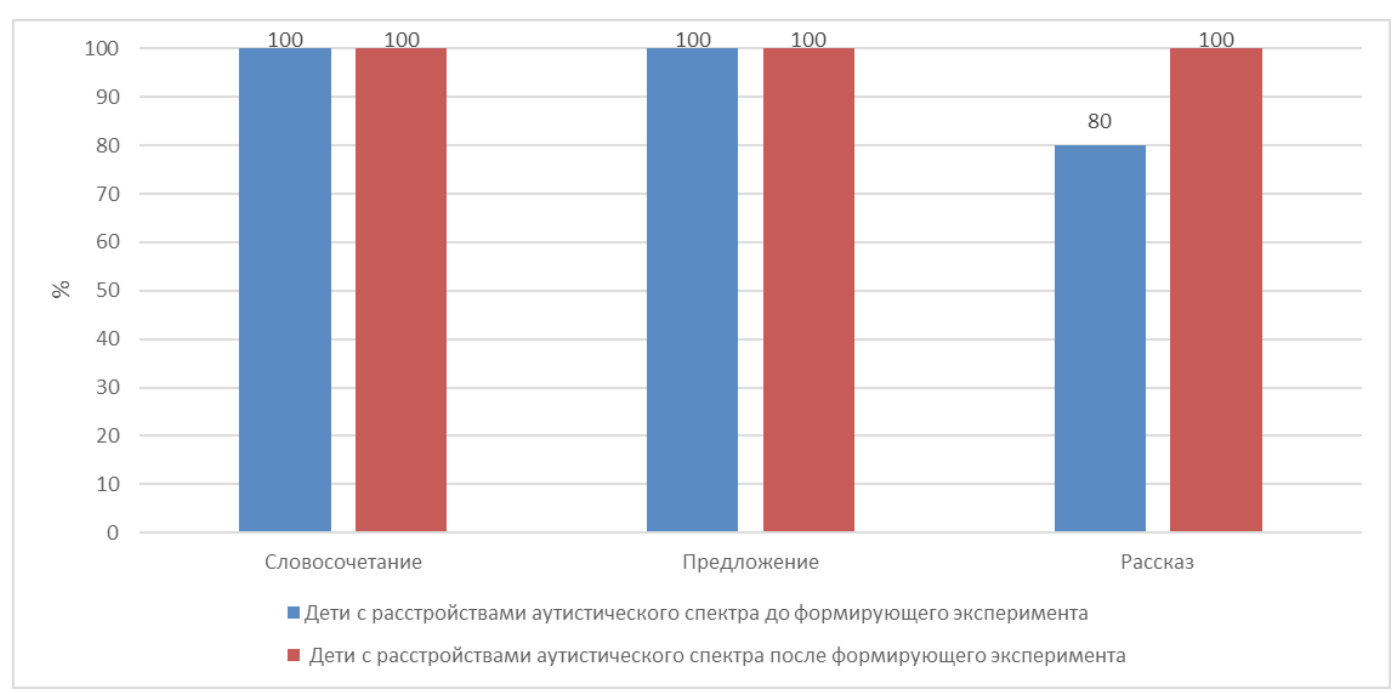

Puc. 7. Результаты оценки фразовых средств речевой коммуникации у старших дошкольников с расстройствами аутистического спектра до и после формирующего эксперимента

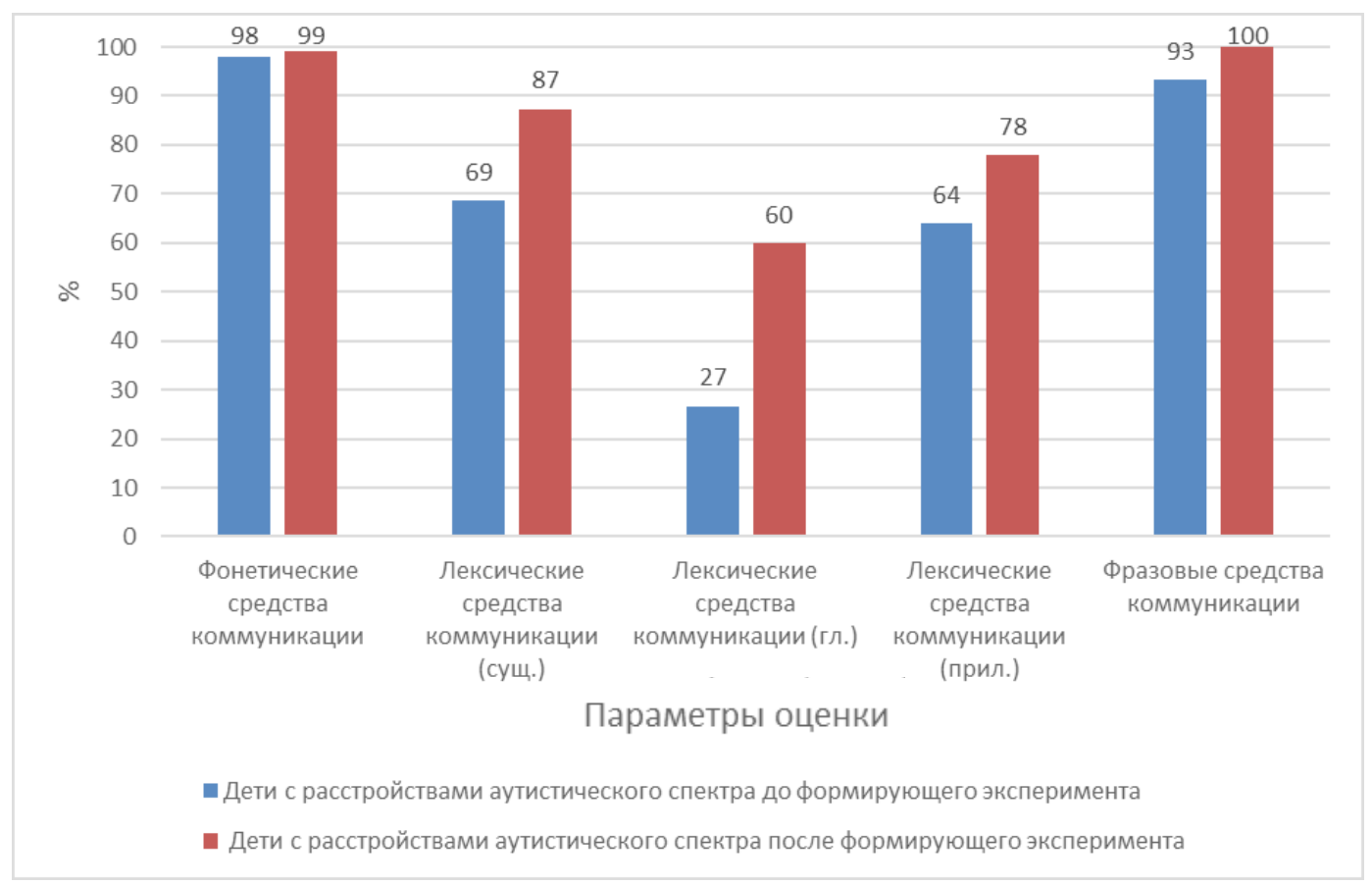

Puc. 8. Результаты оценки средств речевой коммуникации у старших дошкольников с расстройствами аутистического спектра до и после формирующего эксперимента

Грамматическая правильность высказывания и интонационная правильность высказывания речевой коммуникации старших дошкольников с расстройствами аутистического спектра улучшилась в 1,5 раза
(0,7 балла - 70\% от нормативного показателя) по сравнению с результатом первоначальной диагностики $(0,5$ балла $-50 \%$ от нормативного показателя). Дети с аутизмом обращались ко взрослому с познавательны- 
ми вопросами, их обращения стали более эмоциональными, характер обращений свидетельствовал о желании сотрудничества со взрослым.

Сравнительный анализ критерия структурной правильности построения фразы выявил улучшение на 0,2 балла. Показатель увеличился с 0,7 балла до 0,9 балла (70\% и 90\% от нормативного идеального показателя соответственно). Дети с аутизмом стали завершать фразу и использовать правильную последовательность слов.

Параметр наличия исправления речевых ошибок в процессе речевой коммуникации у детей с расстройствами аутистического спектра после формирующего эксперимента улучшился в 3 раза (0,3 балла - 30\% от нормативного показателя). Дети с аутизмом самостоятельно начали исправлять свои неправильно произнесенные слова и используемые предлоги.

Сравнение показателя проявления конгруэнтности вербальных и невербальных средств речевой коммуникаций старших дошкольников с расстройствами аутистического спектра показал увеличение более чем в 1,5 раза после формирующего эксперимента ( 0,5 балла - 50\% от нормативного показателя) по сравнению с первичными результатами (0,3 балла - 30\% от нормативного показателя). У дошкольников стало проявляться соответствие семантики высказывания и сопутствующих действий.

Полученные экспериментальные данные состояния средств регуляции речевой коммуникации старших дошкольников с расстройствами аутистического спектра при общении со взрослыми представлены на рисунке 9.

Сравнительная характеристика результатов оценки состояния мотивации речевой коммуникации старших дошкольников с расстройствами аутистического спектра со сверстниками в процессе игровой деятельности до и после формирующего эксперимента выявила незначительное улучшение показа-

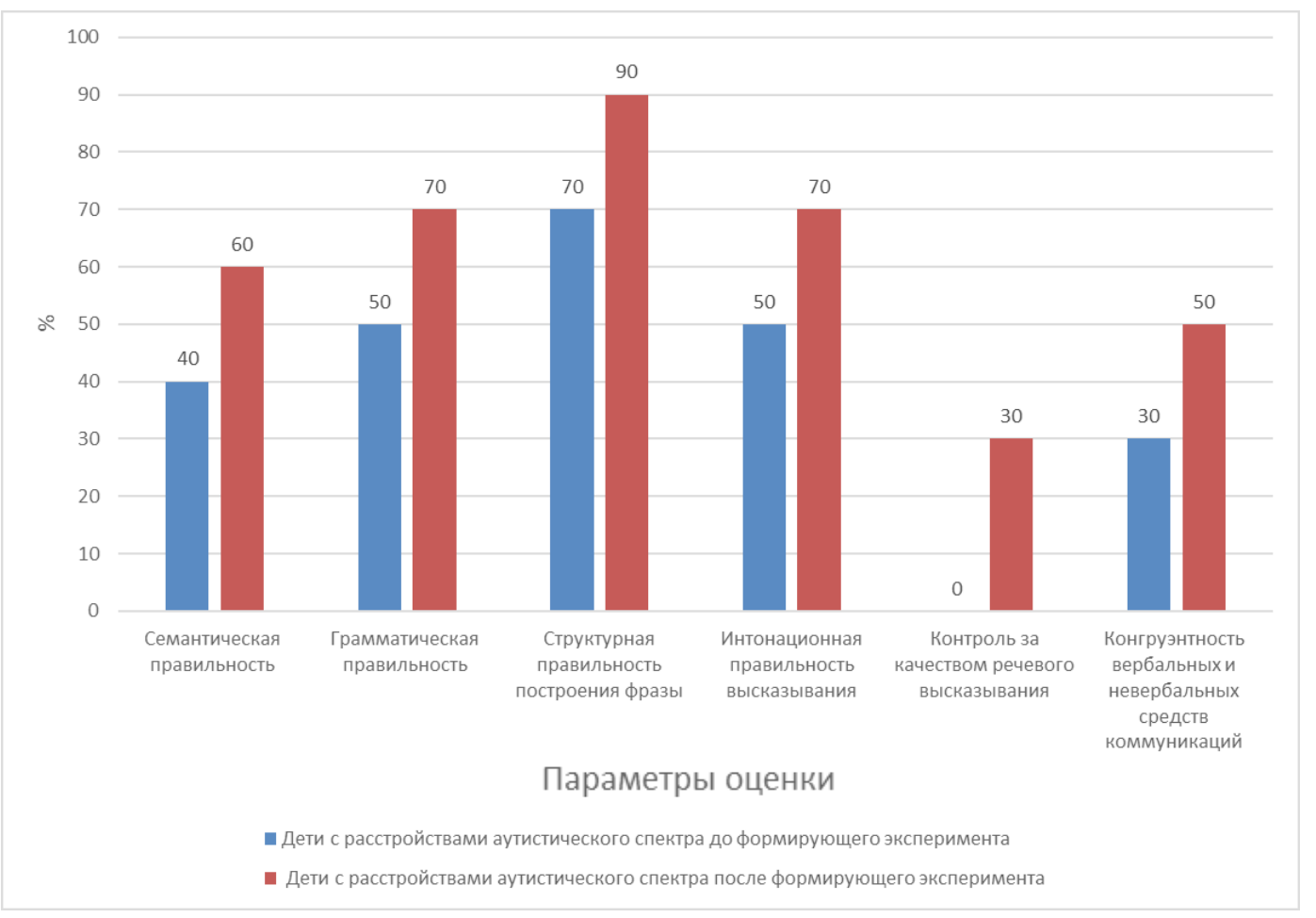

Puc. 9. Результаты оценки средств регуляции речевой коммуникации у старших дошкольников с расстройствами аутистического спектра при общении со взрослыми 
телей: речевой инициативы, наличия речевых ответов, готовности к речевой коммуникации, неречевой реакции и устойчивости контакта примерно в 2 раза. При анализе результатов обследования средств речевой коммуникации старших дошкольников с расстройствами аутистического спектра было выявлено улучшение показателей по всем параметрам. Сравнительная оценка регуляции речевой коммуникации старших дошкольников с расстройствами аутистического спектра при общении со взрослыми выявила динамику роста показателей почти в 1,5 раза.

Сравнение и обработку полученных данных мы проводили по методу достоверности Т-критерию Вилкоксона, который позволяет сравнивать данные в динамике зависимой выборки. Сравнительные данные оценки состояния мотивации речевой коммуникации старших дошкольников с расстройствами аутистического спектра в общении со сверстниками и со взрослыми до и после формирующего эксперимента представлены ниже в таблице 1.

Статистическая значимость оценки мотивации речевой коммуникации старших дошкольников с расстройствами аутистического спектра в общении со сверстниками и со взрослыми до и после формирующего эксперимента выявила достоверность на достаточном уровне $(\mathrm{p}=0,01)$. Сравнительные данные оценки состояния регуляции речевой коммуникации старших дошкольников с расстройствами аутистического спектра в общении со взрослыми до и после формирующего эксперимента представлены ниже в таблице 2.

Таблица 1

Сравнительные результаты оценки мотивации речевой коммуникации старших дошкольников с расстройствами аутистического спектра в общении со взрослыми и со сверстниками до и после формирующего эксперимента

\begin{tabular}{|c|c|c|}
\hline \multirow{2}{*}{ Этапы эксперимента } & \multicolumn{1}{|c|}{$\begin{array}{c}\text { при общении } \\
\text { со сверстниками }\end{array}$} & при общении со взрослыми \\
\cline { 2 - 3 } & \multicolumn{2}{|c|}{ Среднее значение } \\
\hline До формирующего эксперимента & $0,4 \pm 0,2$ & $1,3 \pm 0,4$ \\
\hline После формирующего эксперимента & $1,3 \pm 0,4$ & $3 \pm 0,4$ \\
\hline Достоверность & 0,01 & 0,01 \\
\hline
\end{tabular}

Примечание: достоверность по Т-критерию Вилкоксона при $\mathrm{p} \leq 0,001$.

Таблица 2

Сравнительные результаты оценки регуляции речевой коммуникации старших дошкольников с расстройствами аутистического спектра в общении со взрослыми до и после формирующего эксперимента

\begin{tabular}{|c|c|}
\hline Этапы эксперимента & при общении со взрослыми \\
\cline { 2 - 2 } & Среднее значение \\
\hline До формирующего эксперимента & $0,4 \pm 0,2$ \\
\hline После формирующего эксперимента & $0,6 \pm 0,07$ \\
\hline Достоверность & 0,02 \\
\hline
\end{tabular}

Примечание: достоверность по Т-критерию Вилкоксона при $\mathrm{p} \leq 0,001$. 
Статистическая значимость оценки регуляции речевой коммуникации старших дошкольников с расстройствами аутистического спектра в общении со взрослыми до и после формирующего эксперимента выявила достоверность на достаточном уровне $(\mathrm{p}=0,01)$

Таким образом, полученные результаты контрольного эксперимента, направленного на оценку возможностей коррекции нарушений речевой коммуникации у детей с расстройствами аутистического спектра, позволили нам сделать вывод о том, что первичные расстройства данной категории детей поддаются педагогической компенсации и могут быть корригированы в условиях специально организованной образовательной деятель- ности, нацеленной на формирование мотивации, средств и регуляции речевой коммуникации. Исходя из результатов эксперимента, мы составили рекомендации по совершенствованию программы коррекции нарушений речевой коммуникации старших дошкольников с расстройствами аутистического спектра: увеличить длительность реализации коррекционной работы; использовать интеграционный подход; учесть линейно-концентрический принцип построения программы; использовать в коррекционной работе альтернативные средства коммуникации; использовать совместную продуктивную деятельность детей; дифференцировано использовать комплексы игр и упражнений на развитие речевой коммуникации.

\section{СПИСОК ЛИТЕРАТУРЫ}

1. Гаркуша Ю. Ф., Коржевина В. В. Моделирование коммуникативных ситуаций для развития общения дошкольников с недоразвитием речи // Материалы II Международной научно-практической конференции: Проблемы межкультурной коммуникации в теории языка и лингводидактике: в 2 ч. Ч. 2 / под ред. Т. Г. Пшёнкиной. Барнаул: Барнаульский государственный педагогический университет, 2006. С. 305-308.

2. Лебединская К. С., Никольская О. С. Диагностика раннего детского аутизма: Начальные проявления. М.: Просвещение, 1991.96 с.

3. Мастюкова Е. М. Специальная педагогика. Подготовка к обучению детей с особыми проблемами в развитии: ранний и дошкольный возраст. М.: Классик Стиль, 2003. 320 с.

4. Миронова С. А. Развитие речи дошкольников на логопедических занятиях. Книга для логопеда. M.: Сфера, 2007. 192 c.

\section{REFERENCES}

1. Garkusha Yu. F., Korzhevina V. V. Modelirovanie kommunikativnyh situatsiy dlya razvitiya obshcheniya doshkol'nikov s nedorazvitiem rechi // Materialy II Mezhdunarodnoy nauchno-prakticheskoy konferentsii: Problemy mezhkul'turnoy kommunikatsii v teorii yazyka i lingvodidaktike: v 2 ch. Ch. 2 / pod red. T. G. Pshenkinoy. Barnaul: Barnaul'skiy gosudarstvennyj pedagogicheskiy universitet, 2006. S. 305-308.

2. Lebedinskaya K. S., Nikol'skaya O. S. Diagnostika rannego detskogo autizma: Nachal'nye proyavleniya. M.: Prosveshchenie, $1991.96 \mathrm{~s}$.

3. Mastyukova E. M. Spetsial'naya pedagogika. Podgotovka k obucheniyu detey s osobymi problemami v razvitii: ranniy i doshkol'nyj vozrast. M.: Klassik Stil', 2003. 320 s.

4. Mironova S. A. Razvitie rechi doshkol'nikov na logopedicheskih zanyatiyah. Kniga dlya logopeda. M.: Sfera, 2007. $192 \mathrm{~s}$. 